\title{
Engineering alternative isobutanol production platforms
}

\author{
Carmen Felpeto-Santero ${ }^{1}$, Antonia Rojas², Marta Tortajada², Beatriz Galán', Daniel Ramón² and José L García ${ }^{\text {* }}$
}

\begin{abstract}
A synthetic inducible operon (IbPSO) expressing alsS, ilvC, ilvD and kivD genes encoding a pathway capable to transform pyruvate into 2-isobutyraldehyde has been designed and two recombinant plasmids named plZIbPSO and p424lbPSO were constructed. The IbPSO containing plasmids can generate in a single transformation event new recombinant isobutanol producer strains and are useful for testing as suitable hosts wild type bacteria in different culture media. In this way we found that Shimwellia blattae (p424lbPSO) was able to produce in flasks up to $6 \mathrm{~g} \mathrm{I}^{-1}$ of isobutanol using glucose as carbon source. Moreover, for the first time, we have demonstrated that isobutanol can be produced from sucrose using Escherichia coliW (ATCC9367) transformed with plZIbPSO. These robust recombinant strains were also able to produce isobutanol from a raw carbon source like hydrolysed lignocellulosic biomass.
\end{abstract}

Keywords: Isobutanol, Sucrose, Synthetic operon, E. coli, S. blattae

\section{Introduction}

The growing concerns on climate change have increased the interest in producing new fuels from renewable sources. Although ethanol provides the first model for biofuel commercialization, different efforts have been made to develop new processes for producing novel advanced biofuels such as $\mathrm{C} 3-\mathrm{C} 5$ alcohols containing higher energy density than ethanol. These alcohols are compatible with the current fuel infrastructures since they are less hygroscopic than ethanol. Two examples of these alcohols are 1-butanol and isobutanol that can be blended with gasoline and also can be used for gasoline replacement, as they perform well in conventional gasoline engines. Taking advantage of the increasing genomic information and the rapidly evolving techniques and tools of metabolic engineering, considerable progress has been made toward developing recombinant microbial strains for the production of these new fuels.

Depending on their metabolic capabilities, heterotrophic microorganisms produce central metabolites such as pyruvate and acetyl-CoA using different external

\footnotetext{
*Correspondence: jlgarcia@cib.csic.es

1 Department of Environmental Biology, Centro de Investigaciones

Biológicas, CSIC, Madrid, Spain

Full list of author information is available at the end of the article
}

carbon and energy sources including sugar, glycerol, soluble and insoluble polysaccharides, alginates, proteins and other organic compounds. Biosynthetic pathways for producing higher alcohols elongate and reduce these central metabolites into more electron rich compounds, like higher carbon acyl-CoAs and 2-keto acids. However, only few microorganisms are capable to naturally produce isobutanol in low amounts.

Nowadays it is possible to generate precursors for higher chain alcohol production exploiting the amino acid biosynthesis pathways (Atsumi et al. 2008; Chen et al. 2011; Huo et al. 2011; Kondo et al. 2012; Brat et al. 2012). These pathways produce amino acids through 2-keto acid precursors, which can be used as substrates for the Ehrlich biosynthetic pathway to alcohols that consists of two steps, i.e., a decarboxylation of a 2-keto acid to the corresponding aldehyde by a 2-keto acid decarboxylase, followed by a reduction of the aldehyde by an alcohol dehydrogenase. Using this strategy, a non-natural isobutanol biosynthetic pathway has been created by combining genes from different organisms. In this way isobutanol production has been achieved in several engineered microorganisms (for a summary see Akita et al. 2014) like Escherichia coli (Atsumi et al. 2008; McEwen and Atsumi 2011; Akita et al. 2014), Corynebacterium glutamicum (Blombach et al. 2011), Bacillus subtillis (Li

\section{Springer}


et al. 2011), Saccharomyces cerevisae (Chen et al. 2011; Kondo et al. 2012; Lee et al. 2012), Clostridium cellulolyticum (Higashide et al. 2011), Synechococcus elongatus (Atsumi et al. 2009; Lan and Liao 2013), Pseudomonas sp (Lang et al. 2014) and Ralstonia euthropha (Lu et al. 2012; Li et al. 2012).

Although the synthesis of isobutanol using the keto acid pathway has opened the possibility for its industrial production, the non-native engineered pathways may interfere with the cell metabolism by competing for essential precursors for growth or maintenance. Therefore, to create new fine-tuned pathways that can be perfectly integrated to be compatible with the host cellular metabolism is highly desirable. In this sense, operons have been naturally created to tightly control many pathways and therefore, it appears that assembling the non-natural pathways into well controlled and designed synthetic operons could render some benefits.

In this work we have explored the possibility of constructing a new chemically synthetic operon to transfer the capacity to produce isobutanol to different bacteria, allowing the possibility to test in a simple way many different host organisms as putative isobutanol producers and to regulate it in an integrated manner. Moreover, this approach provides the proof of concept and the opportunity to easily incorporate novel properties to the process (e.g., the use of different raw materials as carbon sources) depending on the strains used as hosts.

\section{Materials and methods}

\section{Bacterial strains, plasmids, growth media} and transformation

The bacterial strains and plasmids used in this study are listed in Table 1. E. coli and Shimwellia blattae strains were cultured in solid LB medium at $37^{\circ} \mathrm{C}$. Antibiotics were used if indicated at the following concentrations: gentamicin $\left(10 \mu \mathrm{g} \mathrm{ml}^{-1}\right)$, streptomycin $\left(50 \mu \mathrm{g} \mathrm{ml}^{-1}\right)$ and ampicillin $\left(100 \mu \mathrm{g} \mathrm{ml}^{-1}\right)$. E. coli and S. blattae recombinant strains were cultured in M9 minimal liquid media containing a mixture of trace elements (nitrilotriacetic acid $1.5 \mathrm{mg} \mathrm{l} \mathrm{l}^{-1}, \mathrm{MgSO}_{4} \cdot 7 \mathrm{H}_{2} \mathrm{O} 3 \mathrm{mg} \mathrm{l}{ }^{-1}, \mathrm{ZnSO}_{4} \cdot 7 \mathrm{H}_{2} \mathrm{O}$ $0.18 \mathrm{mg} \mathrm{l}^{-1}, \mathrm{CuSO}_{4} \cdot 5 \mathrm{H}_{2} \mathrm{O} 0.01 \mathrm{mg} \mathrm{l}{ }^{-1}, \mathrm{MnSO}_{4} \cdot 2 \mathrm{H}_{2} \mathrm{O}$ $0.5 \mathrm{mg} \mathrm{l}^{-1}, \mathrm{NaCl} 1 \mathrm{mg} \mathrm{l}^{-1}, \mathrm{FeSO}_{4} \cdot 7 \mathrm{H}_{2} \mathrm{O} 0.1 \mathrm{mg} \mathrm{l}^{-1}$, $\mathrm{CoSO}_{4} \cdot 7 \mathrm{H}_{2} \mathrm{O} 0.18 \mathrm{mg} \mathrm{l}^{-1}, \mathrm{NaSeO}_{3} \cdot 5 \mathrm{H}_{2} \mathrm{O} 0.3 \mathrm{mg} \mathrm{l}^{-1}$, $\mathrm{KAl}\left(\mathrm{SO}_{4}\right)_{2} \cdot 12 \mathrm{H}_{2} \mathrm{O} \quad 0.02 \mathrm{mg} \mathrm{l}^{-1}, \mathrm{H}_{3} \mathrm{BO}_{3} 0.01 \mathrm{mg} \mathrm{l}^{-1}$, $\mathrm{Na}_{2} \mathrm{MoO} \cdot 2 \mathrm{H}_{2} \mathrm{O} 0.01 \mathrm{mg} \mathrm{l}^{-1}, \mathrm{NiCl}_{2} \cdot 6 \mathrm{H}_{2} \mathrm{O} 0.025 \mathrm{mg} \mathrm{l}^{-1}$ ) according to Atsumi et al. (2010). This medium was always supplemented with yeast extract $\left(5 \mathrm{~g} \mathrm{l}^{-1}\right)$. The sugar carbon sources used in isobutanol production experiments were: glucose $\left(20 \mathrm{~g} \mathrm{l}^{-1}\right)$, xylose $\left(20 \mathrm{~g} \mathrm{l}^{-1}\right)$, sucrose $\left(20 \mathrm{~g} \mathrm{l}^{-1}\right)$, or liquid lignocellulosic hydrolysate (wheat straw partially degraded after treatment with acid and elevated temperatures) being its main components: Glucose $\left(59.16 \mathrm{~g} \mathrm{l}^{-1}\right)$, xylose $\left(27.2 \mathrm{~g} \mathrm{l}^{-1}\right)$, arabinose $\left(3.04 \mathrm{~g} \mathrm{l}^{-1}\right)$, galactose $\left(1.42 \mathrm{~g} \mathrm{l}^{-1}\right)$, cellobiose $\left(1.04 \mathrm{~g} \mathrm{l}^{-1}\right)$, manose $\left(0.55 \mathrm{~g} \mathrm{l}^{-1}\right)$, acetic acid $\left(3.73 \mathrm{~g} \mathrm{l}^{-1}\right)$, formic acid $\left(0.14 \mathrm{~g} \mathrm{l}^{-1}\right)$, hydroxymethylfurfural $\left(0.39 \mathrm{~g} \mathrm{l}^{-1}\right)$, Furfural $\left(0.77 \mathrm{~g} \mathrm{l}^{-1}\right)$, 4-hydroxybenzoic acid $\left(0.009 \mathrm{~g} \mathrm{l}^{-1}\right)$, vanillin $\left(0.029 \mathrm{~g} \mathrm{l}^{-1}\right)$, syringaldehyde $\left(0.016 \mathrm{~g} \mathrm{l}^{-1}\right)$, cumaric acid $\left(0.11 \mathrm{~g} \mathrm{l}^{-1}\right)$, and feluric acid $\left(0.15 \mathrm{~g} \mathrm{l}^{-1}\right)$ (provided by Biopolis S.L.). The hydrolysate was included in the minimal medium at different concentrations as indicated in volume percentages (\% vol/vol, i.e., $\mathrm{ml}$ of liquid hydrolysate in $100 \mathrm{ml}$ of total culture medium). The hydrolysate cannot be used without dilution as a culture medium since it is toxic for the bacteria tested in this study when used at concentrations higher than $50 \%$ (vol/vol). Antibiotics were used for plasmid maintenance at the following concentrations: Gentamicin $\left(10 \mu \mathrm{g} \mathrm{ml}^{-1}\right)$ or streptomycin $\left(50 \mu \mathrm{g} \mathrm{ml}^{-1}\right)$. Cells were cultured overnight in LB $(10 \mathrm{ml})$ in $100 \mathrm{ml}$ flasks at $37^{\circ} \mathrm{C}$ in an orbital shaker at $250 \mathrm{rpm}$. Cells were inoculated at $0.05 \mathrm{OD}_{600 \mathrm{~nm}}$ in production media $(10 \mathrm{ml})$ in $100 \mathrm{ml}$ screw flasks at $37^{\circ} \mathrm{C}$ in an orbital shaker at $250 \mathrm{rpm}$ during $2.5-3 \mathrm{~h}$, until reaching

Table 1 Bacterial strains and plasmids used in this study

\begin{tabular}{|c|c|c|}
\hline Strains & Genotype & References \\
\hline Escherichia coli DH10B & $\begin{array}{l}\mathrm{F}^{-}, \text {mcrA, } \Delta(\mathrm{mrr}-\mathrm{hs} d \mathrm{RMS}-\mathrm{mcrBC}), \text { f80 } \Delta \text { lacZDM15 } \Delta \text { lacX74, deoR, recA1, endA1, araD139, } \\
\quad \Delta\left(\text { ara,leu)7697, galU, galK, rpsL, nupG, } \lambda^{-}\right.\end{array}$ & Invitrogen \\
\hline Escherichia coliW & Type strain. Waksman's strain & ATCC9637 \\
\hline Shimwellia blattae & Type strain & CIP 104942, DSMZ 4481 \\
\hline \multicolumn{3}{|l|}{ Plasmids } \\
\hline pUC57 & $A p^{R}$, pUC-derived cloning vector for E. coli bearing Plac. rep (pMB1) & Genscript \\
\hline plZ1016 & $\mathrm{Gm}^{\mathrm{R}}$, broad-host range expression vector bearing lacla and Ptac. rep (pBBR1MCS) & Martínez-Perez et al. (2004) \\
\hline pSEVA424 & $\begin{array}{l}S m^{R} / S p^{R} \text {, broad-host range expression vector bearing lacla and Ptrc.rep (RK2 replicative origin. } \\
\text { oriV-trfA) }\end{array}$ & Silva-Rocha et al. (2013) \\
\hline pUC57-IbPSO & $A p^{R}$, IbPSO into pUC57 & This work \\
\hline plZIbPSO & $\mathrm{Gm}^{\mathrm{R}}, \mathrm{IbPSO}$ into plZ1016 & This work \\
\hline p424lbPSO & $\mathrm{Sm}^{\mathrm{R}} / \mathrm{Sp} \mathrm{p}^{\mathrm{R}}, \mathrm{IbPSO}$ into pSEVA424 & This work \\
\hline
\end{tabular}


an $\mathrm{OD}_{600 \mathrm{~nm}}$ of 0.5 . Then, cultures were induced by adding $1 \mathrm{mM}$ IPTG and grown at $30^{\circ} \mathrm{C}$ in an orbital shaker at $200 \mathrm{rpm}$ during $48 \mathrm{~h}$. This culture process has been performed either in shake flask or in 96-microwell plates. Culture growth was monitored with a Shimadzu UV-260 spectrophotometer in shaking screw flasks. For the cultivation in 96 -microwell plates, aliquots $(0.2 \mathrm{ml})$ were distributed in the microwells. The plates were incubated at same temperature for $48 \mathrm{~h}$, with $20 \mathrm{~s}$ of heavy orbital shaking every 15 min using a Multiskan Ascent Incubator (Thermo Scientific, Waltham, MA, USA) that monitors optical density at $630 \mathrm{~nm}$ every $60 \mathrm{~min}$. Transformation of bacterial strains was performed by electroporation as previously described (Díaz et al. 1994).

\section{Construction of the synthetic operon}

The synthetic operon (Figure 1) (GenBank accession No. KP739244), named IbPSO, was designed to express the following genes: als $S$ (acetolactate synthase) from $B$. subtilis, ilvC (acetohydroxy acid isomeroreductase) from $E$. coli, ilvD (dihydroxy-acid dehydratase) from E. coli and kivD (2-ketoacid decarboxylase) from Lactococcus lactis. To achieve optimal translation of the mRNA a consensus Shine Dalgarno sequence (AGGAGG) was added

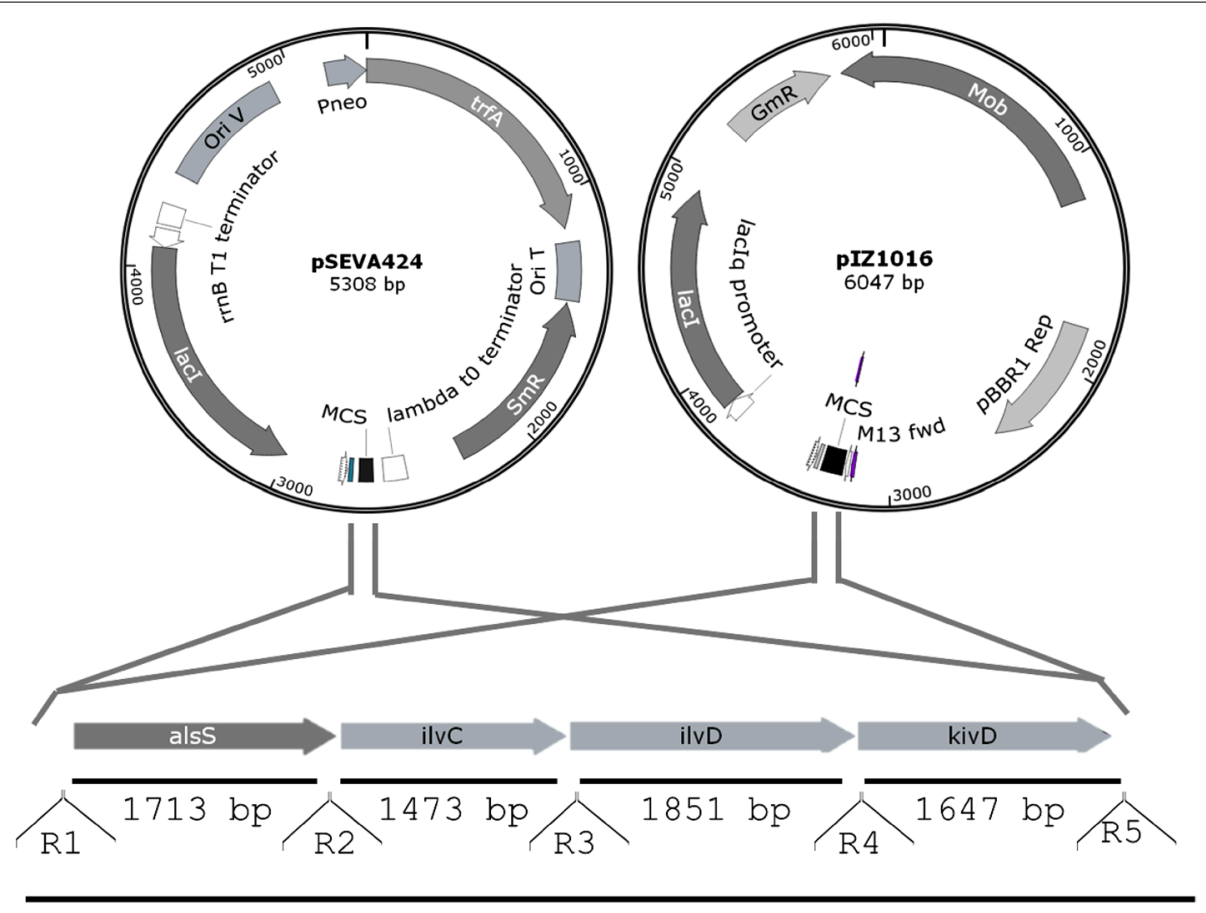

$6774 \mathrm{bp}$

\begin{tabular}{|l|l|}
\hline & \multicolumn{1}{|c|}{ INTERGENIC SEQUENCE } \\
\hline R1 & ACTAGTGATCAATTGAGGAGGACAGCT ( SacI, SpeI and $\mathrm{MfeI}$ ) \\
\hline R2 & GCTAGCAGGAGGAACGTC (Nhel) \\
\hline R3 & CACGTGAGGAGGACGATC $(\mathrm{PmaCl})$ \\
\hline R4 & AGGCCTAGGAGGATCCGA $(\mathrm{Stul})$ \\
\hline R5 & TCTAGA $(\mathrm{Xbal})$ \\
\hline
\end{tabular}

Figure 1 Schematic representation of the genes contained in the IbPSO synthetic operon. The sequences of the intergenic regions (R1-R5) are indicated in the table. The sequences of the restriction sites are underlined and the corresponding restriction enzymes are annotated. The RBS sequences (AGGAGG) are indicated in red. The maps of the two broad host range plasmids, PSEVA424 and plZ1016, used to clone the IbPSO operon are shown. 
upstream each gene at $6 \mathrm{bp}$ from the respective start codons. Restriction enzyme sites were added upstream each gene to facilitate different cloning options. Codon usage was adapted to Gram negative bacteria using the Optimizer program (Puigbó et al. 2007, 2008) at Universitat Rovira i Virgili server (http://genomes.urv.es/OPTIMIZER/). IbPSO operon was chemically synthesized at ATG:biosynthetics $\mathrm{GmbH}$ and was initially cloned into pUC57 generating the plasmid pUC57-IbPSO. Plasmid pUC57-IbPSO was digested with SpeI-XbaI or SacI-XbaI to release the fragment containing the IbPSO operon that was further subcloned into the pIZ1016 (under the control of the Ptac promoter) and pSEVA424 (under the control of Ptrc promoter) vectors, respectively (Figure 1).

\section{HPLC analysis}

For quantification of isobutanol $80 \mu \mathrm{l}$ of culture supernatants were precipitated by the addition of $10 \mu \mathrm{l}$ of both $0.1 \mathrm{M} \mathrm{Ba}(\mathrm{OH})_{2}$ and $0.1 \mathrm{M} \mathrm{ZnSO}_{4}$, and after removing the precipitate by centrifugation at $12,000 \mathrm{~g}$ for $5 \mathrm{~min}$, supernatants were analyzed by HPLC using a Gilson HPLC system equipped with a refraction index detector and an Aminex HPX-87H column $(300 \times 7.8 \mathrm{~mm}$, hydrogen form, $9 \mu \mathrm{m}$ particle size, $8 \%$ cross linkage). The column was eluted isocratically at a flow rate of $0.6 \mathrm{ml} \mathrm{min}$ of $^{-1}$ $5 \mathrm{mM} \mathrm{H}_{2} \mathrm{SO}_{4}$. The analysis was performed using Beckman Coulter's 32 Karat Software 8.0.

\section{Isobutanol and norvaline tolerance test}

To test isobutanol tolerance bacterial strains were inoculated at an $\mathrm{OD}_{600 \mathrm{~nm}}$ of 0.01 in M9 liquid medium supplemented with trace elements as described above, yeast extract $\left(5 \mathrm{~g} \mathrm{l}^{-1}\right)$, glucose $\left(36 \mathrm{~g} \mathrm{l}^{-1}\right)$ and isobutanol $\left(0-10 \mathrm{~g} \mathrm{l}^{-1}\right)$. Growth was determined at $24 \mathrm{~h}$ by determining the O.D at $600 \mathrm{~nm}$. Norvaline tolerance was tested according to Smith and Liao (2011).

\section{Results}

\section{Construction of IbPSO operon}

Atsumi et al. $(2008,2010)$ had designed a non-natural isobutanol production pathway consisting of five enzymatic steps from pyruvate (Figure 2). This pathway combines the alsS, ilvC, kivD, and $A D H 2$ genes that were independently cloned from B. subtilis, E. coli, L. lactis and $S$. cerevisiae, respectively and expressed in several transcription units harbored in at least two compatible plasmids (Atsumi et al. 2008, 2010). The use of two plasmids and different transcription units make this system complex to handle and thus, based on this work we have explored the possibility of designing a new single synthetic isobutanol operon (IbPSO) (see "Materials and methods") to facilitate the cloning and manipulation of this non-natural pathway.

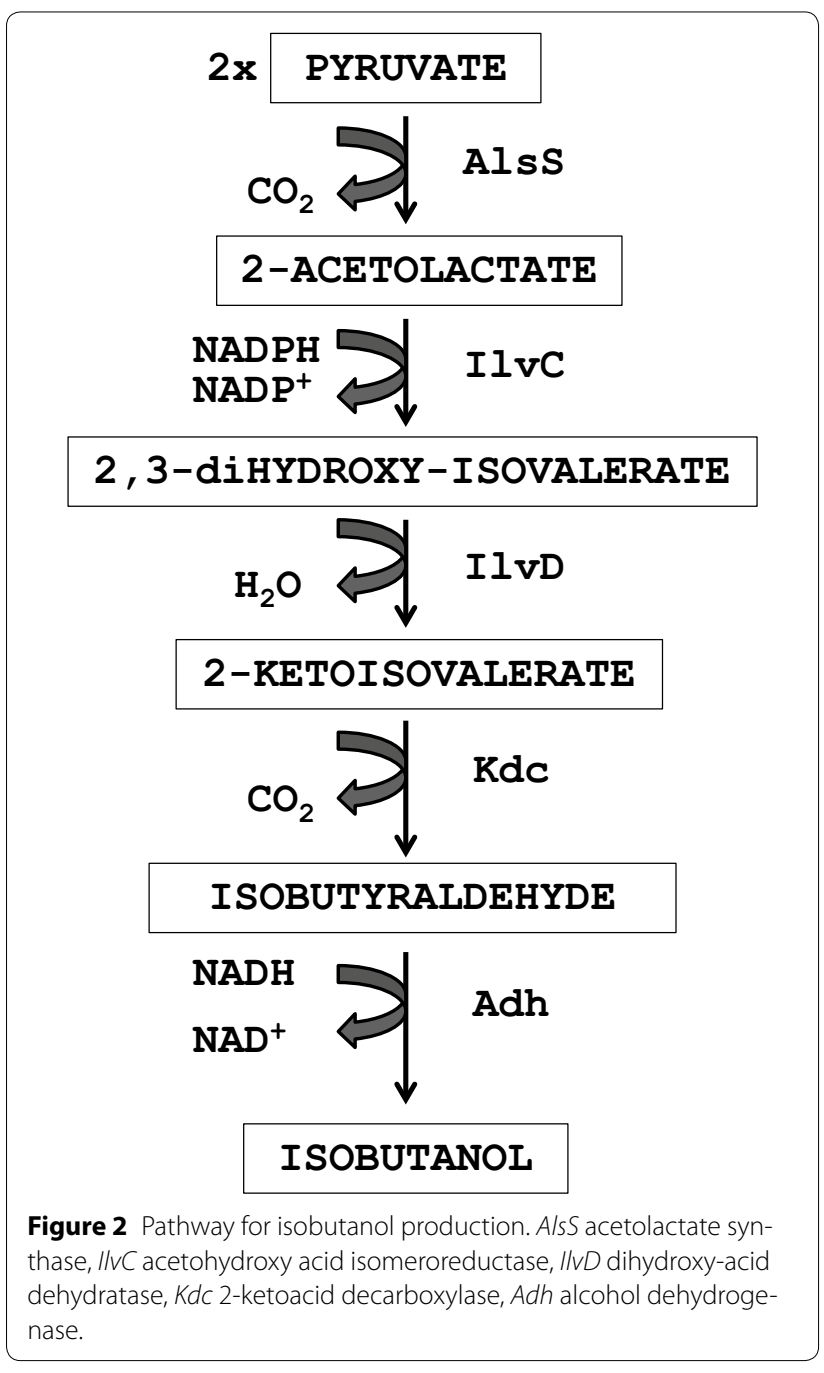

To improve the design of the gene arrangement and reduce its complexity, we have introduced three novelties; (i) the genes were de novo chemically synthesized using a programmed codon use optimal for different bacteria; (ii) the genes were cloned together creating a single transcription unit under the control of a single regulated promoter that can be harbored by a single broad-host-range plasmid or transposon; and (iii) the gene encoding the alcohol dehydrogenase (ADH2) responsible for the last biochemical step (the transformation of 2-isobutyraldehyde to isobutanol) has not been included in the IbPSO operon because as demonstrated by Atsumi et al. (2010) many bacteria possess Adh enzymes that can supply this activity and its inclusion in the operon does not provide additional advantages.

As a proof of concept we have constructed two broadhost range plasmids, pIZIbPSO and p424IbPSO, harbouring the IbPSO operon using E. coli DH10B (K12 
strain) and E. coli CC118 (K12 strain) as hosts, respectively. Plasmid p424IbPSO derives from the synthetic pSEVA424 plasmid, and therefore the new construction has the novelty of being one of the few complete chemically synthetic plasmids used for metabolic engineering so far.

The plasmids were stably maintained in these strains and we confirmed that E. coli DH10B (pIZIbPSO) and E. coli CC118 (p424IbPSO) produced 0.9 and $1.4 \mathrm{~g} \mathrm{l}^{-1}$ of isobutanol, respectively, using glucose as carbon source. These strains only produced isobutanol in the presence of IPTG confirming that the expression of the operon is under the control of the LacI regulator, as expected. These results demonstrated that the new IbPSO synthetic operon was fully functional in E. coli.

The plasmids extracted from these bacteria were further used to create other isobutanol producers with a single transformation event. Because both plasmids have two different broad-host range replication origins and two different antibiotic resistance markers they can be used to transform a large variety of hosts.

\section{Isobutanol overproduction in recombinant strains expressing IbPSO operon}

To test the feasibility of producing isobutanol using the IbPSO operon different strains of Escherichia, Pseudomonas, Shimwellia and Klebsiella were transformed with plasmids pIZIbPSO or p424IbPSO depending of the strains and the possibility of using their antibiotic markers (data not shown). Remarkably, although we were able to obtain antibiotic resistant recombinants in all cases, the plasmids were partially deleted in several hosts. Obviously, only the transformants keeping intact plasmids were able to produce isobutanol in different amounts ranging from milligrams to grams per litter using glucose as carbon source. These results demonstrated that the stability of the plasmids and the isobutanol production were strongly dependent on the host strain. The reasons why the IbPSO containing plasmids were deleted in some strains or why some strains produced more isobutanol than others have not been investigated because the objective was to obtain a battery of isobutanol producers to select the best producing bacteria.

The two best isobutanol producers were E. coli W (ATCC9637) (pIZIbPSO) and S. blattae (p424IbPSO) that were selected for further analyses. The so called "Waksman's strain" or "W strain", E. coli W (ATCC9637) is a fast-growing industrial strain and the only safe (GRAS) strain that can grow using sucrose as sole carbon and energy source. In addition, this strain is able to produce high amounts of L-valine (Park et al. 2011). On the other hand, S. blattae is a non-pathogenic strain that has been used to produce high amounts of 1,3-propanediol (Heinrich et al. 2013).

Figure 3a shows the growth curves of the two strains in the different compounds used as carbon sources to measure the isobutanol production. The best isobutanol producer was $S$. blattae (p424IbPSO) $\left(6 \mathrm{~g} \mathrm{l}^{-1}\right)$ when the microorganism was cultured on glucose, but isobutanol production was also high $\left(>2 \mathrm{gl}^{-1}\right)$ when this strain was cultured in the presence of lignocellulosic hydrolysate or xylose. The strain E. coli W (ATCC 9637) (pIZIbPSO) produced up to $3 \mathrm{~g} \mathrm{l}^{-1}$ in the presence of xylose and $2 \mathrm{~g} \mathrm{l}^{-1}$ when glucose or lignocellulosic hydrolysate were metabolized, but more important this strain also produced $1.7 \mathrm{~g} \mathrm{l}^{-1}$ of isobutanol with sucrose as carbon source. This is the first time that isobutanol has been produced from sucrose. The yields of the transformations are shown in Table 2.

The results demonstrate the potential of the IbPSO strategy, as significant isobutanol productions were achieved even without a comprehensive optimization of the strains and of the operation conditions.

\section{Testing strain tolerance to isobutanol and norvaline}

To investigate whether the higher productions observed in $E$. coli W and S. blattae correlate with their tolerance to isobutanol and/or their overproduction of branched amino acids we tested their resistance to isobutanol and to norvaline, respectively.

Isobutanol is known to be toxic to microbial cells (Brynildsen and Liao 2009) and this feature can be a major restriction to improve productivity. To check isobutanol tolerance the host strains were cultured in liquid medium in the presence of increasing concentration of isobutanol. Figure 4 shows that E. coli W (ATCC 9637) was tolerant to isobutanol up to $7.5 \mathrm{~g} \mathrm{l}^{-1}$. However, $E$. coli DH10B (K12 strain) and S. blattae were less tolerant. None of the tested strains were tolerant to more than $10 \mathrm{~g}^{-1}$ of isobutanol.

Taking into account that norvaline resistance is a property that is related with an improved ability for overproducing branched amino acids in bacteria and that was used for increasing the isobutanol production in $E$. coli (Smith and Liao 2011) we have observed that the better producers E. coli W (ATCC 9637) and S. blattae are able to grow up to $10 \mathrm{mg} \mathrm{l}^{-1}$ of norvaline in contrast with $E$. coli $\mathrm{DH} 10 \mathrm{~B}$ that only resist up to $3 \mathrm{mg} \mathrm{l}^{-1}$ of norvaline. This result confirmed the previous finding that $E$. coli W can grow in media containing up to $50 \mathrm{mM}$ norvaline and $2 \mathrm{mM}$ valine (Park et al. 2011). This result might also explain why E. coli DH10B (pIZIbPSO) in spite of being highly resistant to isobutanol $\left(5 \mathrm{~g} \mathrm{l}^{-1)}\right.$ only produced $0.7 \mathrm{~g} \mathrm{l}^{-1}$ of isobutanol from glucose as carbon source. 


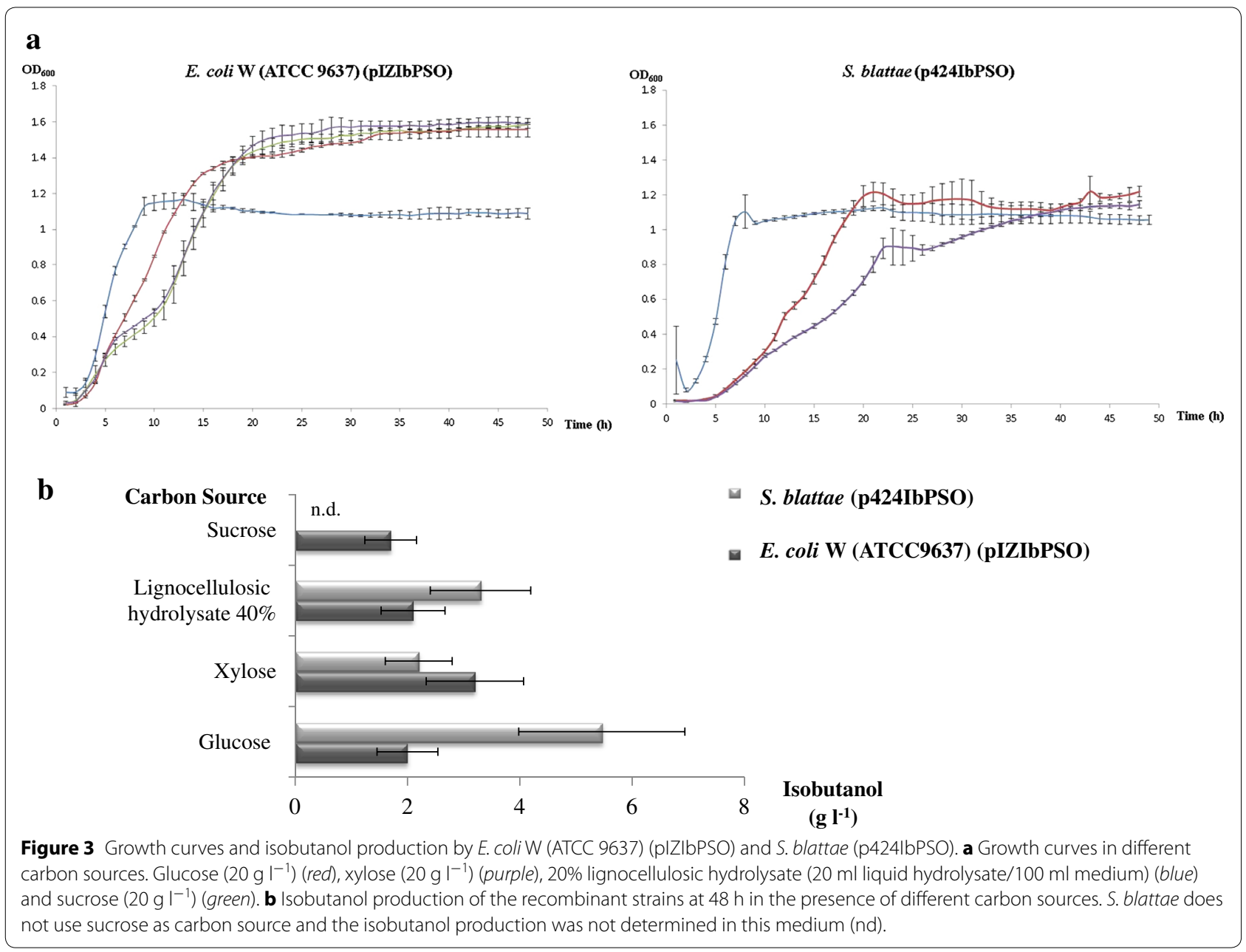

Therefore, resistance to norvaline can be a selective trait to identify the best potential isobutanol producers.

\section{Discussion}

The pioneering work of Liao and co-workers demonstrated that it was possible to transform glucose into isobutanol using engineered microorganisms (Atsumi et al. 2008; Atsumi and Liao 2008; Connor and Liao 2009; Gronenberg et al. 2013). To achieve this objective the producer organism must first convert the carbon source

Table 2 Isobutanol production yields (g/g) with the carbon sources tested

\begin{tabular}{llc}
\hline & E. coliW & S. blattae \\
\hline$Y_{\text {isobutanol/glucose }}$ & 0.095 & 0.196 \\
$Y_{\text {isobutanol/xylose }}$ & 0.160 & 0.123 \\
$Y_{\text {isobutanol/ignocellulosic hydrolysate }}^{a}$ & 0.067 & 0.102 \\
$Y_{\text {isobutanol/sucrose }}$ & 0.204 & n.d. \\
\hline
\end{tabular}

a $24 \mathrm{~g} \mathrm{I}^{-1}$ glucose and $12 \mathrm{~g} \mathrm{I}^{-1}$ xylose. to central metabolic intermediates, which are then transformed into isobutanol through engineered pathways. When using non-conventional resources strain engineering efforts must address problems in both resource utilization and isobutanol synthesis. Therefore, it would be possible to construct the feedstock utilization pathways into an organism that already produces isobutanol, or construct the isobutanol production pathways into a host organism capable of metabolizing the desired resource. The choice of the strategies depends on the complexity of the two types of pathways and difficulties in expressing the enzymes involved (Atsumi et al. 2008; Atsumi and Liao 2008; Connor and Liao 2009; Gronenberg et al. 2013).

With the sole exception of plasmid pJL26 used to produced isobutanol in Ralstonia eutropha (Lu et al. 2012) the existing engineered isobutanol production pathways have been constructed using the native genes obtained from different organisms and these genes have been cloned in pairs or individually in different plasmids. Obviously, this strategy presents several problems: 


\begin{tabular}{|l|} 
F. coli DH10B \\
E. coli $W$ \\
S.blattae
\end{tabular}

(i) the codon use of the genes were not adapted to the host organism; (ii) the genes are expressed in different plasmids which requires the use of several antibiotics and hampers their stability; (iii) the requirement of two or more plasmids complicates their transference to alternative hosts; and (iv) the genes are constructed in different operons making more difficult its regulation.

In order to circumvent these problems we have engineered a completely synthetic pathway in a single operon. The new tools of synthetic biology allowed us not only to optimize the codon usage of the genes but also their transcriptional and translational issues. The genes were placed in the operon according to their metabolic order in the pathway, as occurs on many natural operons. In this way, the complete operon can be uniformly controlled and inserted in a broad range plasmid that can be tested in many different bacteria having diverse metabolic properties.

As a proof of concept we have inserted the new IbPSO operon in two different broad-host range expression vectors, pIZ1016 and pSEVA424, under the control of Ptac and Ptrc promoters, respectively. Therefore, these plasmids allow testing isobutanol production in many different bacteria. Taking into account that pSEVA424 is also a synthetic plasmid, the construction $\mathrm{p} 424 \mathrm{IbPSO}$ is a completely synthetic product.
It is worth to mention that based on the results of Atsumi et al. (2010) we have excluded from the operon the gene encoding for an alcohol dehydrogenase since they have demonstrated that E. coli and other bacteria already contain encoded in their chromosomes widesubstrate-range dehydrogenases (e.g., YqhD or AdhA in $E$. coli) that can efficiently perform the last enzymatic step, i.e., isobutyraldehyde reduction, even better than $\mathrm{ADH} 2$ from $S$. cerevisiae currently used in previous constructions. Moreover, the chromosome expression of these enzymes appears to saturate the enzyme requirements for isobutanol production (Atsumi et al. 2010).

The best isobutanol producer strains constructed so far must be equipped with different mutations in order to achieve a high isobutanol yield, because the recombinants based on the transformation of wild type strains accumulate other intermediates and produce very low isobutanol yields (Atsumi et al. 2008; Atsumi and Liao 2008; Connor and Liao 2009; Gronenberg et al. 2013). One of the best producer strains is E. coli JCL206, a multiple mutant strain ( $\Delta a d h E, \Delta f r d B C, \Delta f n r, \Delta l d h A$, $\Delta p t a, \Delta p f l B)$ derived from $E$. coli K12 strain BW25113, bearing two plasmids, pSA65 and pSA69, that produces about $7 \mathrm{~g} \mathrm{l}^{-1}$ of isobutanol in flasks (Atsumi et al. 2008, 2010) when cultured in similar conditions to that used in this work. This suggests that the recombinant E. coli W (ATCC 9637) and S. blattae strains are good candidates to be improved as isobutanol producers. In this sense it is important to mention that $E$. coli JCL206 (pSA65, pSA69) can produce up to $22 \mathrm{~g} \mathrm{l}^{-1}$ when cultured in higher concentrations of glucose and longer times (Atsumi et al. 2008) or even higher (about $50 \mathrm{~g} \mathrm{l}^{-1}$ ) in bioreactors with in situ product removal (Baez et al. 2011). In this sense, it is very difficult to compare the isobutanol productions described in the literature because when the recombinant bacteria are cultured in flasks, the alcohol is partially evaporated during the fermentation process. Then, to reduce the isobutanol evaporation, flasks must be sealed causing microaerophilic fermentation conditions that do not favour the bacterial growth and are difficult to control and reproduce.

Whether, our recombinant strains of E. coli W (ATCC 9637) and S. blattae can be improved to reach the high isobutanol productions using similar operation conditions that those described for the best producer strains is under study. Moreover, the construction of specific mutants of these new hosts to reduce by-products might still open the possibility of obtaining even best producer strains as demonstrated for other microorganisms (Atsumi et al. 2008; Atsumi and Liao 2008; Connor and Liao 2009; Gronenberg et al. 2013). Nevertheless, it is interesting to notice that during isobutanol productions we have not observed in our recombinant 
strains a significant accumulation in the culture medium of metabolites such as lactic and acetic acids that might reduce the production of isobutanol (data not shown).

On the other hand, the reasons why E. coli W (ATCC 9637) and S. blattae are more robust, produce more isobutanol, and support stably these plasmids better than others tested strains, remain unknown. The analysis of their central and amino acid metabolism based on their genome information did not provide any specific evidence of the existence of specific pathways that might contribute to their robustness. Nevertheless, we suggest that the finding that they are naturally resistant to high concentrations of norvaline might contribute positively.

To produce isobutanol cost effectively on an industrial scale, more economical carbon, nitrogen, and mineral sources should be tested to replace glucose. Sucrose is one of the main feedstock for industrial fermentations presenting several advantages over glucose, such as the fewer amounts of energy, water, and chemicals used for its production which lies in its lower price. Waste molasses from beet and sugar cane contain large amounts of sucrose and they have been used at industrial level as raw materials for different fermentation processes. However, most industrial E. coli strains are derived from the wild types that do not utilize sucrose. In this sense $E$. coli W (ATCC 9637) is able to metabolize sucrose by using the chromosomally encoded sucrose catabolism (csc) regulon. In this work we have demonstrated for the first time that E. coli W (ATCC 9637) (pIZIbPSO) can produce isobutanol from this important raw material. This robust strain appears to be an excellent platform for industrial uses due to its more rapid growth with much less byproduct formation compared with $E$. coli $\mathrm{K}-12$ strains as suggested by Park et al. (2011). On the other hand, the observation that S. blattae and E. coli W (ATCC 9637) grow well on the highly toxic crude lignocellulosic hydrolysates (Figure 3a), has allowed us to produce isobutanol directly using these slurries as carbon sources even containing such toxic mixtures. Because these strains can consume glucose, xylose and arabinose that are the main sugar components of these hydrolysates, these bacteria appear to be ideal for developing an isobutanol production process based on the fermentation of such slurries.

Summarizing, the proof of concept provided in this work opens new avenues to investigate the production of isobutanol using the tools of synthetic biology in order to optimize the production pathways in a simple way and to investigate the utility and adaptability of alternative host strains having different metabolic capabilities to use alternative raw materials or able to work under extreme toxic conditions.

\section{Authors' contribution}

CF-S carried out molecular genetic studies and fermentation experiments and helped to draft the manuscript. AR carried out fermentation experiments and helped to draft the manuscript. MT and BG participated in the design of the study and helped to draft the manuscript. DR conceived the study and helped to draft the manuscript. JLG designed and coordinated the study and drafted the manuscript. All authors read and approved the final manuscript.

\section{Author details}

${ }^{1}$ Department of Environmental Biology, Centro de Investigaciones Biológicas, CSIC, Madrid, Spain. ${ }^{2}$ Biopolis S.L., Parc Científic Universitat de Valencia, Paterna, Spain.

\section{Acknowledgements}

We are deeply indebted to Prof. E. Santero (CABD-CSIC/UPO, Seville, Spain) for providing plZ1016 plasmid and Prof. V. de Lorenzo (CNB-CSIC, Madrid, Spain) for providing pSEVA424 plasmid. We want to thank A. Valencia, F. de la Peña and Dr. V. Morales for technical support. This work was supported by grants from Biopolis S.L. and Spanish Ministry of Science and Innovation BIOSOS CEN20091040 (CENIT-CDTI). We acknowledge support of the publication fee by the CSIC Open Access Publication Support Initiative through its Unit of Information Resources for Research (URICl).

\section{Compliance with ethical guidelines}

\section{Competing interests}

The authors declare that they have no competing interests.

Received: 13 May 2015 Accepted: 18 May 2015

Published online: 04 June 2015

\section{References}

Akita H, Nkashima N, Hoshino T (2014) Bacterial production of isobutanol without expensive reagents. Appl Microbiol Biotechnol. doi:10.1007/ s00253-014-6173-x

Atsumi S, Liao JC (2008) Metabolic engineering for advanced biofuels production from Escherichia coli. Curr Opin Biotechnol 195:414-419

Atsumi S, Hanai T, Liao JC (2008) Non-fermentative pathways for synthesis of branched-chain higher alcohols as biofuels. Nature 451:86-89

Atsumi S, Higashide W, Liao JC (2009) Direct photosynthetic recycling of carbon dioxide to isobutyraldehyde. Nat Biotechnol 27:1177-1180

Atsumi S, Wu TY, Eckl EM, Hawkins SD, Buelter T, Liao JC (2010) Engineering the isobutanol biosynthetic pathway in Escherichia coli by comparison of three aldehyde reductase/alcohol dehydrogenase genes. Appl Microbiol Biotechnol 85:651-657

Baez A, Cho KM, Liao JC (2011) High-flux isobutanol production using engineered Escherichia coli, a bioreactor study with in situ product removal. Appl Microbiol Biotechnol 90:1681-1690

Blombach B, Riester T, Wieschalka S, Ziert C, Youn JW, Wendisch VF et al (2011) Corynebacterium glutamicum tailored for efficient isobutanol production. Appl Environ Microbiol 77:3300-3310

Brat D, Weber C, Lorenzen W, Bode H, Boles E (2012) Cytosolic re-localization and optimization of valine synthesis and catabolism enables increased isobutanol production with the yeast Saccharomyces cerevisiae. Biotechnol Biofuels 5:65

Brynildsen MP, Liao JC (2009) An integrated network approach identifies the isobutanol response network of Escherichia coli. Mol Syst Biol 5:277

Chen X, Nielsen KF, Borodina I, Kielland-Brandt MC, Karhumaa K (2011) Increased isobutanol production in Saccharomyces cerevisiae by overexpression of genes in valine metabolism. Biotechnol Biofuels 4:21

Connor MR, Liao JC (2009) Microbial production of advanced transportation fuels in non-natural hosts. Curr Opin Biotechnol 20:307-315

Díaz E, Munthali M, de Lorenzo V, Timmis KN (1994) Universal barrier to lateral spread of specific genes among microorganisms. Mol Microbiol 13:855-861

Gronenberg LS, Marcheschi RJ, Liao JC (2013) Next generation biofuel engineering in prokaryotes. Curr Opin Chem Biol 17:462-471 
Heinrich D, Andreessen B, Madkour MH, Al-Ghamdi MA, Shabbaj II, Steinbüchel A (2013) From waste to plastic, synthesis of poly3-hydroxypropionate in Shimwellia blattae. Appl Environ Microbiol 79:3582-3589

Higashide W, Li Y, Yang Y, Liao JC (2011) Metabolic engineering of Clostridium cellulolyticum for production of isobutanol from cellulose. Appl Environ Microbiol 77:2727-2733

Huo YX, Cho KM, Rivera JG, Monte E, Shen CR, Yan Y et al (2011) Conversion of proteins into biofuels by engineering nitrogen flux. Nat Biotechnol 29:346-351

Kondo T, Tezuka H, Ishii J, Matsuda F, Ogino C, Kondo A (2012) Genetic engineering to enhance the Ehrlich pathway and alter carbon flux for increased isobutanol production from glucose by Saccharomyces cerevisiae. J Biotechnol 159:32-37

Lan El, Liao JC (2013) Microbial synthesis of $n$-butanol, isobutanol, and other higher alcohols from diverse resources. Bioresour Technol 135:339-349

Lang K, Zierow J, Buehler K, Schmid A (2014) Metabolic engineering of Pseudomonas sp. strain VLB120 as platform biocatalyst for the production of isobutyric acid and other secondary metabolites. Microb Cell Fact 13:2

Lee WH, Seo SO, Bae YH, Nan H, Jin YS, Seo JH (2012) Isobutanol production in engineered Saccharomyces cerevisiae by overexpression of 2-ketoisovalerate decarboxylase and valine biosynthetic enzymes. Bioprocess Biosyst Eng 35:1467-1475

Li S, Wen J, Jia X (2011) Engineering Bacillus subtilis for isobutanol production by heterologous Ehrlich pathway construction and the biosynthetic 2-ketoisovalerate precursor pathway overexpression. Appl Microbiol Biotechnol 91:577-589
Li H, Opgenorth PH, Wernick DG, Rogers S, Wu TY, Higashide W et al (2012) Integrated electromicrobial conversion of $\mathrm{CO}_{2}$ to higher alcohols. Science 335:1596

Lu J, Brigham CJ, Gai CS, Sinskey AJ (2012) Studies on the production of branched-chain alcohols in engineered Ralstonia eutropha. Appl Microbiol Biotechnol 96:283-297

Martínez-Perez O, Moreno-Ruiz E, Floriano B, Santero E (2004) Regulation of tetralin biodegradation and identification of genes essential for expression of thn operons. J Bacteriol 186:6101-6109

McEwen JT, Atsumi S (2011) Alternative biofuel production in non-natural hosts. Curr Opin Biotechnol 23:1-7

Park JH, Jang YS, Lee JW, Lee SY (2011) Escherichia coli W as a new platform strain for the enhanced production of L-valine by systems metabolic engineering. Biotechnol Bioeng 108:1140-1147

Puigbó P, Guzmán E, Romeu A, Garcia-Vallvé S (2007) OPTIMIZER, a web server for optimizing the codon usage of DNA sequences. Nucl Acids Res 35:W126-W131

Puigbó P, Romeu A, Garcia-Vallvé S (2008) HEG-DB, a database of predicted highly expressed genes in prokaryotic complete genomes under translational selection. Nucl Acids Res 36:D524-D527

Silva-Rocha R, Martínez-García E, Calles B, Chavarría M, Arce-Rodríguez A, de las Heras A et al (2013) The Standard Europea Vector Architecture SEVA, a coherent platform for the analysis and deployment of complex prokaryotic phenotypes. Nucl Acids Res 41D1:D666-D675

Smith KM, Liao JC (2011) An evolutionary strategy for isobutanol production strain development in Escherichia coli. Metab Eng 13:674-681

\section{Submit your manuscript to a SpringerOpen ${ }^{\circ}$ journal and benefit from:}

- Convenient online submission

- Rigorous peer review

- Immediate publication on acceptance

- Open access: articles freely available online

- High visibility within the field

- Retaining the copyright to your article

Submit your next manuscript at $>$ springeropen.com 